\title{
Numerical Simulation of 1D Unsteady Heat Conduction-Convection in Spherical and Cylindrical Coordinates by Fourth-Order FDM
}

\author{
Leticia Helena Paulino de Assis \\ Basic and Environmental Sciences Department \\ University of Sao Paulo \\ Lorena, Sao Paulo, Brazil \\ leticia.hpa@alunos.eel.usp.br
}

\author{
Estaner Claro Romao \\ Basic and Environmental Sciences Department \\ University of Sao Paulo \\ Lorena, Sao Paulo, Brazil \\ estaner23@usp.br
}

\begin{abstract}
This paper aims to apply the Fourth Order Finite Difference Method (FDM) to solve the one-dimensional unsteady conduction-convection equation with energy generation (or sink) in cylindrical and spherical coordinates. Two applications were compared through exact solutions to demonstrate the accuracy of the proposed formulation.
\end{abstract}

Keywords-central difference method; cylindrical and spherical coordinates; numerical simulation; numerical efficiency

\section{INTRODUCTION}

According to [1], conduction refers to the transport of energy in a medium due to the temperature gradient. The onedimensional convection-diffusion equations with transient heat generation were solved by the Fourth-Order FDM. The transient regime arises with the change of boundary conditions. If the surface temperature of a system is changed, the temperature of each point of that system will change until it reaches a stationary temperature distribution. It is important to emphasize that the idea of using the Fourth Order Finite Difference Method has already been successfully implemented in [2-6] for problems set in Cartesian coordinates, and thus, the same idea in cylindrical and spherical coordinates is now proposed. This paper will investigate numerically the onedimensional unsteady convection-diffusion equations with heat generation in cylindrical and spherical coordinates. From $[1,7]$, we have the equations, respectively,

$$
\begin{aligned}
& \rho c_{p}\left(\frac{\partial T}{\partial t}+v_{r} \frac{\partial T}{\partial r}\right)=k\left(\frac{1}{r} \frac{\partial}{\partial r}\left(r \frac{\partial T}{\partial r}\right)\right)+\dot{q} \\
& \rho c_{p}\left(\frac{\partial T}{\partial t}+v_{r} \frac{\partial T}{\partial r}\right)=k\left(\frac{1}{r^{2}} \frac{\partial}{\partial r}\left(r^{2} \frac{\partial T}{\partial r}\right)\right)+\dot{q}
\end{aligned}
$$

where $\mathrm{T}(\mathrm{r}, \mathrm{t})$ is the temperature $(\mathrm{K}), r$ is the cylindrical or spherical coordinates $(\mathrm{m}), k$ is the thermal conductivity (W/m.K), $\rho$ is the specific mass $\left(\mathrm{kg} / \mathrm{m}^{3}\right), \mathrm{c}_{\mathrm{p}}$ is the specific heat at constant pressure (J/kg.K) and $q$ is the energy generation $(\mathrm{K} / \mathrm{s})$.

\section{NUMERICAL FORMULATION}

Before starting the numerical formulation of (1)-(2), we rearrange these equations as follows,

$$
\begin{aligned}
& \frac{\partial T}{\partial t}=\left(\frac{\alpha}{r}-v_{r}\right) \frac{\partial T}{\partial r}+\alpha \frac{\partial^{2} T}{\partial r^{2}}+\frac{\dot{q}}{\rho c_{p}} \\
& \frac{\partial T}{\partial t}=\left(\frac{2 \alpha}{r}-v_{r}\right) \frac{\partial T}{\partial r}+\alpha \frac{\partial^{2} T}{\partial r^{2}}+\frac{\dot{q}}{\rho c_{p}}
\end{aligned}
$$

where $\alpha\left(\mathrm{m}^{2} / \mathrm{s}\right)$ is the thermal diffusivity with $\alpha=k / \rho c_{p}$.

\section{A. Temporal Discretization}

For Temporal Discretization of the (3) and (4) will be used the Crank-Nicolson Method [8], as follows,

$$
\begin{aligned}
& T^{n+1}=0.5 \Delta t\left[\alpha\left(\frac{\partial^{2} T^{n+1}}{\partial r^{2}}\right)+\left(\frac{\alpha}{r}-v_{r}\right)\left(\frac{\partial T^{n+1}}{\partial r}\right)+\left(\frac{\dot{q}}{\rho c_{p}}\right)^{n+1}\right. \\
& \left.+\alpha\left(\frac{\partial^{2} T^{n}}{\partial r^{2}}\right)+\left(\frac{\alpha}{r}-v_{r}\right)\left(\frac{\partial T^{n}}{\partial r}\right)+\left(\frac{\dot{q}}{\rho c_{p}}\right)^{n}\right]+T^{n}
\end{aligned}
$$

and

$$
\begin{aligned}
& T^{n+1}=0.5 \Delta t\left[\alpha\left(\frac{\partial^{2} T^{n+1}}{\partial r^{2}}\right)+\left(\frac{2 \alpha}{r}-v_{r}\right)\left(\frac{\partial T^{n+1}}{\partial r}\right)+\left(\frac{\dot{q}}{\rho c_{p}}\right)^{n+1}\right. \\
& \left.+\alpha\left(\frac{\partial^{2} T^{n}}{\partial r^{2}}\right)+\left(\frac{2 \alpha}{r}-v_{r}\right)\left(\frac{\partial T^{n}}{\partial r}\right)+\left(\frac{\dot{q}}{\rho c_{p}}\right)^{n}\right]+T^{n}
\end{aligned}
$$

\section{B. Spatial Discretization}

Following the formulation, the Spatial Discretization using High-Order Finite Difference Method for internal nodes will be 
realized according to the following (i.e. the same principle used in [8]).

\section{1) Internal nodes}

In the internal nodes of the computational mesh, the following fourth-order central finite differences were used to discretize the first and second order partial derivatives, respectively [7-9],

$$
\begin{aligned}
& \frac{\partial T}{\partial r}=\frac{-T_{i+2}+8 T_{i+1}-8 T_{i-1}+T_{i-2}}{12 \Delta r} \\
& \frac{\partial^{2} T}{\partial r^{2}}=\frac{-T_{i+2}+16 T_{i+1}-30 T_{i}+16 T_{i-1}-T_{i-2}}{12 \Delta r^{2}}
\end{aligned}
$$

which when replaced in (5) and (6), obtain the expressions, for cylindrical and spherical coordinates, respectively,

$$
\begin{aligned}
& \left(\frac{\alpha \Delta t}{24 \Delta r^{2}}-\frac{\alpha \Delta t}{24 r \Delta r}+\frac{v_{r} \Delta t}{24 \Delta r}\right) T_{i-2}^{n+1}-\left(\frac{2 \alpha \Delta t}{3 \Delta r^{2}}-\frac{\alpha \Delta t}{3 r \Delta r}+\frac{v_{r} \Delta t}{3 \Delta r}\right) T_{i-1}^{n+1} \\
& +\left(1+\frac{5 \alpha \Delta t}{4 \Delta r^{2}}\right) T_{i}^{n+1}-\left(\frac{2 \alpha \Delta t}{3 \Delta r^{2}}+\frac{\alpha \Delta t}{3 r \Delta r}-\frac{v_{r} \Delta t}{3 \Delta r}\right) T_{i+1}^{n+1} \\
& +\left(\frac{\alpha \Delta t}{24 \Delta r^{2}}+\frac{\alpha \Delta t}{24 r \Delta r}-\frac{v_{r} \Delta t}{24 \Delta r}\right) T_{i+2}^{n+1}=\frac{0.5 \Delta t \dot{q}^{n+1}}{\rho c_{p}} \\
& +\left(\frac{-\alpha \Delta t}{24 \Delta r^{2}}+\frac{\alpha \Delta t}{24 r \Delta r}-\frac{v_{r} \Delta t}{24 \Delta r}\right) T_{i-2}^{n}+\left(\frac{2 \alpha \Delta t}{3 \Delta r^{2}}-\frac{\alpha \Delta t}{3 r \Delta r}+\frac{v_{r} \Delta t}{3 \Delta r}\right) T_{i-1}^{n} \\
& +\left(1-\frac{5 \alpha \Delta t}{4 \Delta r^{2}}\right) T_{i}^{n}+\left(\frac{2 \alpha \Delta t}{3 \Delta r^{2}}+\frac{\alpha \Delta t}{3 r \Delta r}-\frac{v_{r} \Delta t}{3 \Delta r}\right) T_{i+1}^{n} \\
& +\left(\frac{-\alpha \Delta t}{24 \Delta r^{2}}-\frac{\alpha \Delta t}{24 r \Delta r}+\frac{v_{r} \Delta t}{24 \Delta r}\right) T_{i+2}^{n}+\frac{0.5 \Delta t \dot{q}^{n}}{\rho c_{p}}
\end{aligned}
$$

and

$$
\begin{aligned}
& \left(\frac{\alpha \Delta t}{24 \Delta r^{2}}-\frac{\alpha \Delta t}{12 r \Delta r}+\frac{v_{r} \Delta t}{24 \Delta r}\right) T_{i-2}^{n+1}-\left(\frac{2 \alpha \Delta t}{3 \Delta r^{2}}-\frac{2 \alpha \Delta t}{3 r \Delta r}+\frac{v_{r} \Delta t}{3 \Delta r}\right) T_{i-1}^{n+1} \\
& +\left(1+\frac{5 \alpha \Delta t}{4 \Delta r^{2}}\right) T_{i}^{n+1}-\left(\frac{2 \alpha \Delta t}{3 \Delta r^{2}}+\frac{2 \alpha \Delta t}{3 r \Delta r}-\frac{v_{r} \Delta t}{3 \Delta r}\right) T_{i+1}^{n+1} \\
& +\left(\frac{\alpha \Delta t}{24 \Delta r^{2}}+\frac{\alpha \Delta t}{12 r \Delta r}-\frac{v_{r} \Delta t}{24 \Delta r}\right) T_{i+2}^{n+1}=\frac{0.5 \Delta t \dot{q}^{n+1}}{\rho c_{p}} \\
& +\left(\frac{-\alpha \Delta t}{24 \Delta r^{2}}+\frac{\alpha \Delta t}{12 r \Delta r}-\frac{v_{r} \Delta t}{24 \Delta r}\right) T_{i-2}^{n}+\left(\frac{2 \alpha \Delta t}{3 \Delta r^{2}}-\frac{2 \alpha \Delta t}{3 r \Delta r}+\frac{v_{r} \Delta t}{3 \Delta r}\right) T_{i-1}^{n} \\
& +\left(1-\frac{5 \alpha \Delta t}{4 \Delta r^{2}}\right) T_{i}^{n}+\left(\frac{2 \alpha \Delta t}{3 \Delta r^{2}}+\frac{2 \alpha \Delta t}{3 r \Delta r}-\frac{v_{r} \Delta t}{3 \Delta r}\right) T_{i+1}^{n} \\
& +\left(\frac{-\alpha \Delta t}{24 \Delta r^{2}}-\frac{\alpha \Delta t}{12 r \Delta r}+\frac{v_{r} \Delta t}{24 \Delta r}\right) T_{i+2}^{n}+\frac{0.5 \Delta t \dot{q}^{n}}{\rho c_{p}}
\end{aligned}
$$

2) Nodes distant $\Delta r$ of the boundary
For discretization of nodes near the boundary it is not possible to use (7) and (8), for example, a node at a distance $\Delta r$ from the boundary will not have two nodes to its left. Thus, for these nodes (5) and (6) will be used to discretize the following second order central finite difference,

$$
\begin{aligned}
& \frac{\partial T}{\partial r}=\frac{T_{i+1}-T_{i-1}}{2 \Delta r} \\
& \frac{\partial^{2} T}{\partial r^{2}}=\frac{T_{i+1}-2 T_{i}+T_{i-1}}{\Delta r^{2}}
\end{aligned}
$$

and thus when applying (11) and (12) in (5) and (6), we result in,

$$
\begin{aligned}
& \left(\frac{-\alpha \Delta t}{2 \Delta r^{2}}+\frac{\alpha \Delta t}{4 r \Delta r}-\frac{v_{r} \Delta t}{4 \Delta r}\right) T_{i-1}^{n+1}+\left(1+\frac{\alpha \Delta t}{\Delta r^{2}}\right) T_{i}^{n+1} \\
& -\left(\frac{\alpha \Delta t}{2 \Delta r^{2}}+\frac{\alpha \Delta t}{4 r \Delta r}-\frac{v_{r} \Delta t}{4 \Delta r}\right) T_{i+1}^{n+1}=\frac{0.5 \Delta t \dot{q}^{n+1}}{\rho c_{p}} \\
& +\left(\frac{\alpha \Delta t}{2 \Delta r^{2}}-\frac{\alpha \Delta t}{4 r \Delta r}+\frac{v_{r} \Delta t}{4 \Delta r}\right) T_{i-1}^{n}+\left(1-\frac{\alpha \Delta t}{\Delta r^{2}}\right) T_{i}^{n} \\
& +\left(\frac{\alpha \Delta t}{2 \Delta r^{2}}+\frac{\alpha \Delta t}{4 r \Delta r}-\frac{v_{r} \Delta t}{4 \Delta r}\right) T_{i+1}^{n}+\frac{0.5 \Delta t \dot{q}^{n}}{\rho c_{p}} \\
& \quad\left(\frac{-\alpha \Delta t}{2 \Delta r^{2}}+\frac{\alpha \Delta t}{2 r \Delta r}-\frac{v_{r} \Delta t}{4 \Delta r}\right) T_{i-1}^{n+1}+\left(1+\frac{\alpha \Delta t}{\Delta r^{2}}\right) T_{i}^{n+1} \\
& \quad-\left(\frac{\alpha \Delta t}{2 \Delta r^{2}}+\frac{\alpha \Delta t}{2 r \Delta r}-\frac{v_{r} \Delta t}{4 \Delta r}\right) T_{i+1}^{n+1}=\frac{0.5 \Delta t \dot{q}^{n+1}}{\rho c_{p}} \\
& +\left(\frac{\alpha \Delta t}{2 \Delta r^{2}}-\frac{\alpha \Delta t}{2 r \Delta r}+\frac{v_{r} \Delta t}{4 \Delta r}\right) T_{i-1}^{n}+\left(1-\frac{\alpha \Delta t}{\Delta r^{2}}\right) T_{i}^{n} \\
& +\left(\frac{\alpha \Delta t}{2 \Delta r^{2}}+\frac{\alpha \Delta t}{2 r \Delta r}-\frac{v_{r} \Delta t}{4 \Delta r}\right) T_{i+1}^{n}+\frac{0.5 \Delta t \dot{q}^{n}}{\rho c_{p}}
\end{aligned}
$$

In summary, (9) and (13) construct the linear system that solves the problem governed by (5) (cylindrical coordinates) and (10) and (14) solve the problem governed by (6) (spherical coordinates).

\section{NUMERICAL APPLICATIONS}

Linear systems are set, using (9) and (13) for cylindrical coordinates and (10) and (14) for spherical coordinates, and solved using Fortran. The values of temperature in all nodes of the computational mesh were constructed in predetermined domains. In both applications it was considered that $0.5 \leq r \leq 1$, $0 \leq t \leq 1, \rho=c_{p}=\alpha=1$ and $v_{r}=1$.

1) Application 1 .

The exact solution proposed is given by $T(r, t)=e^{r+t}$. From (3) and (4) we obtain, in cylindrical and spherical coordinates, respectively, 


$$
\begin{aligned}
& \dot{q}=\rho c_{p} e^{r+t}\left(1+v_{r}-\frac{\alpha}{r}-\alpha\right) \\
& \dot{q}=\rho c_{p} e^{r+t}\left(1+v_{r}-\frac{2 \alpha}{r}-\alpha\right)
\end{aligned}
$$

By the variation of $\Delta r$ and $\Delta t$, the influence of the temporal and spatial refinements was studied, by comparing the results of the numerical solutions and the exact solution, as shown in Tables I and II. What can be noticed in Tables I and II is that with the refinement in space and time, the numerical precision improves with each greater refinement, as expected. In order to show the numerical efficiency of the proposed formulation, and remembering that in many cases numerical formulations are not very efficient in cases of highly convective problems, Table III presents, the numerical precision for some values of $v_{r}$ for the two types of refinements. It is clear that for the $v_{r}$ values adopted, the formulation continues to have excellent numerical precision.

TABLE I. ERRORS FOR DIFFERENT VALUES OF VARIATION IN SPACE AND TIME IN CYLINDRICAL COORDINATES, APPLICATION 1

\begin{tabular}{|c|c|c|c|c|c|}
\hline & \multicolumn{5}{|c|}{$\Delta \boldsymbol{t}$} \\
\hline$\Delta \boldsymbol{r}$ & $\mathbf{1 0}^{-\mathbf{1}}$ & $\mathbf{5}_{\mathbf{1 0}} \mathbf{1 0}^{-\mathbf{2}}$ & $\mathbf{2 \times \mathbf { 1 0 } ^ { - \mathbf { 2 } }}$ & $\mathbf{1 0}^{-\mathbf{2}}$ & $\mathbf{1 0}^{-\mathbf{3}}$ \\
\hline $\mathbf{5} \times \mathbf{1 0}^{-\mathbf{2}}$ & $1.56 \mathrm{E}-04$ & $4.33 \mathrm{E}-05$ & $1.19 \mathrm{E}-05$ & $7.77 \mathrm{E}-06$ & $6.85 \mathrm{E}-06$ \\
\hline $\mathbf{2 . 5} \times \mathbf{1 0}^{-\mathbf{2}}$ & $1.50 \mathrm{E}-04$ & $3.78 \mathrm{E}-05$ & $6.36 \mathrm{E}-06$ & $1.87 \mathrm{E}-06$ & $4.68 \mathrm{E}-07$ \\
\hline $\mathbf{1 0}^{-2}$ & $1.50 \mathrm{E}-04$ & $3.75 \mathrm{E}-05$ & $6.00 \mathrm{E}-06$ & $1.51 \mathrm{E}-06$ & $2.46 \mathrm{E}-08$ \\
\hline $\mathbf{5} \times \mathbf{1 0}^{-3}$ & $1.50 \mathrm{E}-04$ & $3.75 \mathrm{E}-05$ & $6.00 \mathrm{E}-06$ & $1.49 \mathrm{E}-06$ & $1.56 \mathrm{E}-08$ \\
\hline
\end{tabular}

TABLE II. ERRORS FOR DIFFERENT VALUES OF VARIATION IN SPACE AND TIME IN SPHERICAL COORDINATES, APPLICATION 1

\begin{tabular}{|c|c|c|c|c|c|}
\hline & \multicolumn{5}{|c|}{$\Delta \mathbf{t}$} \\
\hline$\Delta \boldsymbol{r}$ & $\mathbf{1 0}^{-\mathbf{1}}$ & $\mathbf{5}_{\mathbf{1 0}} \mathbf{1 0}^{-\mathbf{2}}$ & $\mathbf{2} \times \mathbf{1 0}^{-\mathbf{2}}$ & $\mathbf{1 0}^{-\mathbf{2}}$ & $\mathbf{1 0}^{-\mathbf{3}}$ \\
\hline $\mathbf{5} \times \mathbf{1 0}^{-\mathbf{2}}$ & $1.67 \mathrm{E}-04$ & $5.28 \mathrm{E}-05$ & $2.15 \mathrm{E}-05$ & $1.80 \mathrm{E}-05$ & $1.70 \mathrm{E}-05$ \\
\hline $\mathbf{2 . 5} \times \mathbf{1 0}^{-2}$ & $1.53 \mathrm{E}-04$ & $3.88 \mathrm{E}-05$ & $7.00 \mathrm{E}-06$ & $2.47 \mathrm{E}-06$ & $1.12 \mathrm{E}-06$ \\
\hline $\mathbf{1 0}^{-2}$ & $1.52 \mathrm{E}-04$ & $3.79 \mathrm{E}-05$ & $6.09 \mathrm{E}-06$ & $1.54 \mathrm{E}-06$ & $3.97 \mathrm{E}-08$ \\
\hline $\mathbf{5}^{\mathbf{1 0} \mathbf{1 0}^{-3}}$ & $1.52 \mathrm{E}-04$ & $3.79 \mathrm{E}-05$ & $6.07 \mathrm{E}-06$ & $1.52 \mathrm{E}-06$ & $1.67 \mathrm{E}-08$ \\
\hline
\end{tabular}

TABLE III. ERRORS FOR DIFFERENT VALUES OF $V_{r}$, APPLICATION 1

\begin{tabular}{|c|c|c|c|c|}
\hline \multirow{2}{*}{$\boldsymbol{v}$} & \multicolumn{2}{r}{$\Delta \boldsymbol{r}=\mathbf{5} \times \mathbf{1 0}^{-\mathbf{2}}$ and $\boldsymbol{\Delta} \boldsymbol{t}=\mathbf{1 0}^{-\mathbf{1}}$} & \multicolumn{2}{c|}{$\boldsymbol{\Delta} \boldsymbol{r}=\mathbf{5} \times \mathbf{1 0}^{-\mathbf{3}}$ and $\boldsymbol{\Delta t}=\mathbf{1 0}^{-\mathbf{3}}$} \\
\cline { 2 - 5 } & Cylindrical & Spherical & Cylindrical & Spherical \\
\hline $\mathbf{0 . 1}$ & $1.62 \mathrm{E}-04$ & $1.71 \mathrm{E}-04$ & $1.62 \mathrm{E}-08$ & $1.71 \mathrm{E}-08$ \\
\hline $\mathbf{0 . 5}$ & $1.55 \mathrm{E}-04$ & $1.69 \mathrm{E}-04$ & $1.59 \mathrm{E}-08$ & $1.69 \mathrm{E}-08$ \\
\hline $\mathbf{1}$ & $1.56 \mathrm{E}-04$ & $1.67 \mathrm{E}-04$ & $1.56 \mathrm{E}-08$ & $1.67 \mathrm{E}-08$ \\
\hline $\mathbf{2}$ & $1.48 \mathrm{E}-04$ & $1.61 \mathrm{E}-04$ & $1.49 \mathrm{E}-08$ & $1.61 \mathrm{E}-08$ \\
\hline $\mathbf{5}$ & $1.22 \mathrm{E}-04$ & $1.36 \mathrm{E}-04$ & $1.23 \mathrm{E}-08$ & $1.39 \mathrm{E}-08$ \\
\hline $\mathbf{1 0}$ & $7.32 \mathrm{E}-05$ & $8.90 \mathrm{E}-05$ & $7.40 \mathrm{E}-09$ & $9.10 \mathrm{E}-09$ \\
\hline $\mathbf{2 0}$ & $5.49 \mathrm{E}-05$ & $4.56 \mathrm{E}-05$ & $1.43 \mathrm{E}-08$ & $1.34 \mathrm{E}-08$ \\
\hline
\end{tabular}

\section{2) Application 2 .}

The exact solution proposed is given by $T(r, t)=\sin (2(r+$ t)). From (3) and (4) we obtain, in cylindrical and spherical coordinates, respectively,

$$
2\left(1+v_{r}-\frac{\alpha}{r}\right) \cos (2(r+t))+4 \alpha \sin (2(r+t))=\frac{\dot{q}}{\rho c_{p}}
$$

$$
2\left(1+v_{r}-\frac{2 \alpha}{r}\right) \cos (2(r+t))+4 \alpha \sin (2(r+t))=\frac{\dot{q}}{\rho c_{p}}
$$

By the variation of $\Delta \mathrm{r}$ and $\Delta \mathrm{t}$, the influence of the temporal and spatial refinements was studied, by comparing the results of the numerical solutions and the exact solution, as shown in Tables IV and V. It is observed from Tables IV and V that the numerical precision obtained in Application 2 is extremely similar to that presented in Application 1, meaning that the formulation proposed in this work behaved well for two types of exact solutions, exponential and sine. Table VI presents, for the two types of refinements the precision for various values of $v_{r}$. The method's efficiency is clearly shown as in Application 1.

TABLE IV. ERRORS FOR DIFFERENT VALUES OF VARIATION IN SPACE AND TIME IN CYLINDRICAL COORDINATES, APPLICATION 2

\begin{tabular}{|c|c|c|c|c|c|}
\hline & \multicolumn{5}{|c|}{$\Delta \boldsymbol{t}$} \\
\hline$\Delta \boldsymbol{r}$ & $\mathbf{1 0}^{-1}$ & $\mathbf{5} \times \mathbf{1 0}^{-\mathbf{2}}$ & $\mathbf{2} \times \mathbf{1 0}^{-\mathbf{2}}$ & $\mathbf{1 0}^{-2}$ & $\mathbf{1 0}^{-\mathbf{3}}$ \\
\hline $\mathbf{5 \times 1 0 ^ { - 2 }}$ & $2.02 \mathrm{E}-04$ & $5.11 \mathrm{E}-05$ & $1.11 \mathrm{E}-05$ & $7.22 \mathrm{E}-06$ & $6.46 \mathrm{E}-06$ \\
\hline $\mathbf{2 . 5} \times \mathbf{1 0}^{-\mathbf{2}}$ & $1.99 \mathrm{E}-04$ & $4.96 \mathrm{E}-05$ & $8.06 \mathrm{E}-06$ & $2.13 \mathrm{E}-06$ & $5.17 \mathrm{E}-07$ \\
\hline $\mathbf{1 0}^{-2}$ & $1.99 \mathrm{E}-04$ & $4.96 \mathrm{E}-05$ & $7.93 \mathrm{E}-06$ & $1.99 \mathrm{E}-06$ & $2.56 \mathrm{E}-08$ \\
\hline${\mathbf{5} \times \mathbf{1 0}^{-3}}^{1.99 \mathrm{E}-04}$ & $4.96 \mathrm{E}-05$ & $7.93 \mathrm{E}-06$ & $1.98 \mathrm{E}-06$ & $2.01 \mathrm{E}-08$ \\
\hline
\end{tabular}

TABLE V. ERRORS FOR DIFFERENT VALUES OF VARIATION IN SPACE AND TIME IN SPHERICAL COORDINATES, APPLICATION 2

\begin{tabular}{|c|c|c|c|c|c|}
\hline & \multicolumn{5}{|c|}{$\Delta \boldsymbol{t}$} \\
\hline$\Delta \boldsymbol{r}$ & $\mathbf{1 0}^{-1}$ & $\mathbf{5} \times \mathbf{1 0}^{-\mathbf{2}}$ & $\mathbf{2} \times \mathbf{1 0}^{-2}$ & $\mathbf{1 0}^{-2}$ & $\mathbf{1 0}^{-\mathbf{2}}$ \\
\hline $\mathbf{5} \times \mathbf{1 0}^{-\mathbf{2}}$ & $2.14 \mathrm{E}-04$ & $6.46 \mathrm{E}-05$ & $2.65 \mathrm{E}-05$ & $2.30 \mathrm{E}-05$ & $2.22 \mathrm{E}-05$ \\
\hline $\mathbf{2 . 5} \times \mathbf{1 0}^{-2}$ & $2.02 \mathrm{E}-04$ & $5.09 \mathrm{E}-05$ & $8.87 \mathrm{E}-06$ & $2.96 \mathrm{E}-06$ & $1.56 \mathrm{E}-06$ \\
\hline $\mathbf{1 0}^{-2}$ & $2.01 \mathrm{E}-04$ & $5.00 \mathrm{E}-05$ & $8.02 \mathrm{E}-06$ & $2.02 \mathrm{E}-06$ & $4.94 \mathrm{E}-08$ \\
\hline${\mathbf{5} \times \mathbf{1 0}^{-3}}^{2}$ & $2.01 \mathrm{E}-04$ & $5.00 \mathrm{E}-05$ & $8.00 \mathrm{E}-06$ & $2.00 \mathrm{E}-06$ & $2.14 \mathrm{E}-08$ \\
\hline
\end{tabular}

TABLE VI. ERRORS FOR DIFFERENT VALUES OF $V_{r}$, APPLICATION 2

\begin{tabular}{|c|c|c|c|c|}
\hline \multirow{2}{*}{$v_{\boldsymbol{r}}$} & \multicolumn{2}{|c|}{$\Delta \boldsymbol{r}=\mathbf{5} \times \mathbf{1 0}^{-\mathbf{2}}$ and $\boldsymbol{\Delta} \boldsymbol{t}=\mathbf{1 0}^{-\mathbf{1}}$} & \multicolumn{2}{c|}{$\Delta \boldsymbol{r}=\mathbf{5} \times \mathbf{1 0}^{-\mathbf{3}}$ and $\boldsymbol{\Delta} \boldsymbol{t}=\mathbf{1 0}^{-\mathbf{3}}$} \\
\cline { 2 - 5 } & $\mathbf{C y l i n d r i c a l}$ & Spherical & Cylindrical & Spherical \\
\hline $\mathbf{0 . 1}$ & $2.05 \mathrm{E}-04$ & $2.19 \mathrm{E}-04$ & $2.06 \mathrm{E}-08$ & $2.17 \mathrm{E}-08$ \\
\hline $\mathbf{0 . 5}$ & $2.03 \mathrm{E}-04$ & $2.17 \mathrm{E}-04$ & $2.04 \mathrm{E}-08$ & $2.16 \mathrm{E}-08$ \\
\hline $\mathbf{1}$ & $2.00 \mathrm{E}-04$ & $2.14 \mathrm{E}-04$ & $2.01 \mathrm{E}-08$ & $2.14 \mathrm{E}-08$ \\
\hline $\mathbf{2}$ & $1.92 \mathrm{E}-04$ & $2.07 \mathrm{E}-04$ & $1.93 \mathrm{E}-08$ & $2.09 \mathrm{E}-08$ \\
\hline $\mathbf{5}$ & $1.57 \mathrm{E}-04$ & $1.80 \mathrm{E}-04$ & $1.60 \mathrm{E}-08$ & $1.83 \mathrm{E}-08$ \\
\hline $\mathbf{1 0}$ & $9.01 \mathrm{E}-05$ & $1.13 \mathrm{E}-04$ & $8.74 \mathrm{E}-09$ & $1.14 \mathrm{E}-08$ \\
\hline $\mathbf{2 0}$ & $1.10 \mathrm{E}-04$ & $9.82 \mathrm{E}-05$ & $1.60 \mathrm{E}-08$ & $1.42 \mathrm{E}-08$ \\
\hline
\end{tabular}

\section{CONCLUSION}

The Fourth Order Finite Difference Method (FDM) was employed to solve the one-dimensional unsteady conductionconvection equation with energy generation in cylindrical and spherical coordinates. Two applications were compared to demonstrate the accuracy of the proposed formulation. An improvement in result-terms was documented. It was observed that both spatial and time refinements were effective, but time was found to be more effective. The errors obtained in cylindrical and spherical coordinates were low and satisfactory, in both applications tested.

\section{ACKNOWLEDGEMENTS}

The FAPESP (Procs. 2014/06679-8 and 2016/16867-1) and CNPq (Proc. 400898/2016-0) supported the present work. 


\section{REFERENCES}

[1] T. L. Bergman, A. S. Lavine, F. P. Incropera, D. De Witt, Fundamentals of Heat and Mass Transfer, Fifth Edition, John Wiley \& Sons, 2003

[2] E. C. Romao, J. C. Z. Aguillar, M. D. Campos, L. F. M. de Moura, "Central difference method of $\mathrm{O}\left(\Delta x^{6}\right)$ in solution of the CDR equation with variable coefficients and Robin condition", International Journal of Applied Mathematics, Vol. 25, No. 1, pp. 139-153, 2012

[3] M. D. Campos, E. C. Romao, L. F. M. de Moura, "A Finite-Difference Method of High-Order Accuracy for the Solution of Transient Nonlinear Diffusive-Convective Problem in Three Dimensions", Case Studies in Thermal Engineering, Vol. 3, pp. 43-50, 2014

[4] M. M. Cruz, M. D. Campos, J. A. Martins, E. C. Romao, “An Efficient Technique of Linearization towards Fourth Order Finite Differences for Numerical Solution of the 1D Burgers Equation", Defect and Diffusion Forum, Vol. 348, pp. 285-290, 2014

[5] S. F. Radwan, "Comparison of higher-order accurate schemes for solving the two-dimensional unsteady Burgers' equation", Journal of Computational and Applied Mathematics, Vol. 174, No. 2, pp. 383-397, 2005

[6] M. Cui, "Convergence analysis of high-order compact alternating direction implicit schemes for the two-dimensional time fractional diffusion equation", Numerical Algorithms, Vol. 62, No. 3, pp. 383-409, 2013.

[7] J. R. Welty, C. E. Wilson, G. L. Rorrer, Fundamental of Heat and Mass Transfer, 4th ed., Wiley, 2001

[8] M .D. Campos, E. C. Romao, "A High-Order Finite-Difference Scheme with a Linearization Technique for Solving of Three-Dimensional Burgers Equation", Computer Modeling in Engineering \& Sciences, Vol. 103, pp. 139-154, 2014

[9] T. J. Chung, Computational fluid dynamics, Cambridge University Press, 2002 